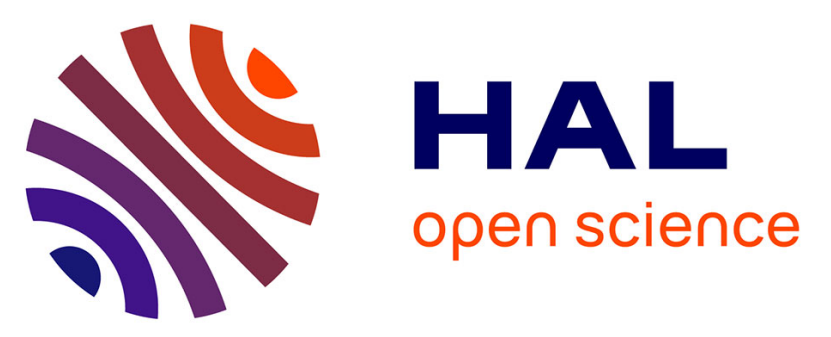

\title{
FOLFIRINOX-based neoadjuvant chemoradiotherapy for borderline and locally advanced pancreatic cancer: A pilot study from a tertiary centre
}

Claudia Pouypoudat, Etienne Buscail, Sébastien Cossin, Christophe Cassinotto, Eric Terrebonne, Jean-Frédéric Blanc, Denis Smith, Marion

Marty, Charles Dupin, Christophe Laurent, et al.

\section{To cite this version:}

Claudia Pouypoudat, Etienne Buscail, Sébastien Cossin, Christophe Cassinotto, Eric Terrebonne, et al.. FOLFIRINOX-based neoadjuvant chemoradiotherapy for borderline and locally advanced pancreatic cancer: A pilot study from a tertiary centre. Digestive and Liver Disease, 2019, 51, pp.1043 1049. 10.1016/j.dld.2019.03.004 . hal-03484383

\section{HAL Id: hal-03484383 \\ https://hal.science/hal-03484383}

Submitted on 20 Dec 2021

HAL is a multi-disciplinary open access archive for the deposit and dissemination of scientific research documents, whether they are published or not. The documents may come from teaching and research institutions in France or abroad, or from public or private research centers.
L'archive ouverte pluridisciplinaire HAL, est destinée au dépôt et à la diffusion de documents scientifiques de niveau recherche, publiés ou non, émanant des établissements d'enseignement et de recherche français ou étrangers, des laboratoires publics ou privés.

\section{(ㅇ)(1) $\$$}

Distributed under a Creative Commons Attribution - NonCommerciall 4.0 International 


\section{DLD-18-692-R3}

Title: FOLFIRINOX-based neoadjuvant chemoradiotherapy for borderline and locally advanced pancreatic cancer: a pilot study from a tertiary centre

Authors : Claudia Pouypoudat $(M D)^{1}$, Etienne Buscail $(M D)^{2-3}$, Sébastien Cossin (MD) ${ }^{4}$, Christophe Cassinotto $(\mathrm{MD}, \mathrm{PhD})^{5}$, Eric Terrebonne $(\mathrm{MD})^{6}$, Jean-Frédéric Blanc $(\mathrm{MD}, \mathrm{PhD})^{6}$, Denis Smith $(\mathrm{MD})^{6}$, Marion Marty $(\mathrm{MD})^{7}$, Charles Dupin $(\mathrm{MD})^{1}$, Christophe Laurent $(\mathrm{MD}, \mathrm{PhD})^{2-3}$, Sandrine Dabernat $(\mathrm{PhD})^{2}$, Laurence Chiche $(\mathrm{MD})^{2-3}$, Véronique Vendrely $(\mathrm{MD}, \mathrm{PhD})^{1-2}$

1- CHU Bordeaux, Department of Radiotherapy, F-33000 Bordeaux, France

2- Bordeaux University, INSERM U1035, F-33000 Bordeaux, France

3- CHU Bordeaux, Department of Surgery, F-33000 Bordeaux, France

4- ISPED Bordeaux, F-33000 Bordeaux, France

5- CHU Bordeaux, Department of Radiology, F-33000 Bordeaux, France

6- CHU Bordeaux, Department of Oncology, F-33000 Bordeaux, France

7- CHU Bordeaux, Dpartment of Pathology, F-33000 Bordeaux, France

Corresponding author: Dr Véronique Vendrely

Radiotherapy Department, Haut-Lévêque Hospital, CHU de Bordeaux

Avenue de Magellan, 33604 Pessac Cédex, France

Tel: (+33) 557623300 Fax: (+ 33) 557623305

E-mail: veronique.vendrely@chu-bordeaux.fr

\section{Funding:}

This research did not receive any specific grant from funding agencies in the public, commercial, or not-for-profit sectors 
Title: FOLFIRINOX-based neoadjuvant chemoradiotherapy for borderline and locally advanced pancreatic cancer: a pilot study from a tertiary centre

\section{Abstract}

Background: Neoadjuvant chemoradiotherapy, potentially relevant to increase resection rate in pancreatic cancer, is still debated.

Aims: To assess tolerance, resection rate and outcomes of patients with non-metastatic pancreatic ductal adenocarcinoma treated by concomitant chemoradiotherapy.

Methods: This monocentric study included all consecutive patients treated from 2010 to 2014 for non-metastatic pancreatic adenocarcinoma. Chemotherapy was followed by chemoradiotherapy in operable patients, surgical resectability being assessed by CT-scan.

Results: Seventy-nine patients were included: 41 patients had borderline and 38 locally advanced tumours. All patients were treated by chemotherapy (FOLFIRINOX), followed by chemoradiotherapy (median dose: $59 \mathrm{~Gy}$, range $45-66 \mathrm{~Gy}$ ) for $94 \%$ of patients. Thirty-seven patients (47\%) could subsequently benefit from surgery with a complete RO resection in $94 \%$ of cases, with a postoperative mortality of 5\%. Median overall survival was 21.5 months (median follow-up: 48.8 months). Local control, overall and disease-free survival were significantly higher for patients who underwent resection compared to others, with $89.2 \%$ vs $59.5 \%(p=0.01), 49.7$ vs 17.4 months $(p<0.01)$ and 25.5 vs 9.2 months $(p<0.01)$, respectively.

Conclusion: Neoadjuvant treatment consisting of FOLFIRINOX chemotherapy followed by chemoradiotherapy is an efficient strategy for patients with borderline and locally advanced pancreatic cancer, resulting in a $43 \%$ rate of secondary complete surgical resection associated with high local control, overall and disease-free survival.

Keywords: Pancreatic adenocarcinoma, neoadjuvant treatment, radiotherapy, chemotherapy, pancreatic surgical resection, chemoradiotherapy. 


\section{Introduction}

Pancreatic ductal adenocarcinoma (PDAC) is associated with a poor prognosis since 5-year global survival rate is around $5 \%$ (1). About 30 to $40 \%$ of patients have a locoregional non-metastatic disease at time of diagnosis, i.e. either resectable or unresectable tumours. Given that surgery with clear resection margins (i.e. R0 resection) is the only curative option (2), the question of resectability has been widely discussed in order to define criteria that could guide the treatment strategy. In 2017, the National Comprehensive Cancer Network (NCCN) updated their classification distinguishing locoregional disease in resectable cancers, borderline potentially resectable (BR) and unresectable locally advanced (LA) PDAC based on venous and/or arterial invasion status (3). On the one hand, unresectable LA PDAC is treated by induction chemotherapy, possibly followed by chemoradiotherapy, resulting in secondary resection in about $20 \%$ of cases (4). On the other hand, upfront surgery of BR cancers is associated with a high rate of microscopically incomplete resection (i.e. R1 resection) (5). Therefore, for patients with BR or LA PDAC, there is a strong rationale for neoadjuvant therapy with the aim of converting unresectable tumours to resectable for LA PDACs and increasing the rate of RO resections for BR cancers. Gillen's meta-analysis (111 studies, 4394 patients) showed that neoadjuvant chemoradiotherapy resulted in a secondary resection rate of 33.2\% for LA initially unresectable cancers (4). During the past couple of decades, the strategy in our institution was to treat LA PDAC by neoadjuvant chemotherapy followed by exclusive chemoradiotherapy but with systematic assessment by CT-scan at the end of treatment. Good responders were then considered for surgery. More recently, this regimen has been extended to $B R$ tumours as a neoadjuvant strategy because of their high rate of R1 resections (6).

The aim of the study was to assess the secondary resection rate and the overall and disease-free survival of patients with BR or LA PDAC treated by concomitant chemoradiotherapy in a prospective observational cohort. 


\section{Methods and Materials}

This retrospective intent to treat analysis of a monocentric prospective observational cohort included all consecutive patients treated by FOLFIRINOX chemotherapy, followed by chemoradiotherapy or not, from January 2010 to December 2014 for BR and LA PDAC. The treatment strategy for every patient was decided on clinical data and CT-scan images by a multidisciplinary team (MDT: at least one oncologist, surgeon, radiologist, gastroenterologist and pathologist).The study was approved by the institutional review board and the need for written informed consent was waived.

\section{Initial staging}

All tumours were cytologically or histologically proven by echoendoscopic ultrasound-guided fine needle aspiration. Tumours were classified by the multidisciplinary team as LA or BR on CT-scan images, $1.25 \mathrm{~mm}$ slices, with arterial and portal contrast infusion. Knowing that the classification between LA and BR tumours could be a major bias in our analysis, all baseline CT-scans were reviewed retrospectively by a senior radiologist, and tumours reclassified with strict accordance to NCCN classification v2-2017 (3). Post chemoradiotherapy staging was assessed by CT-scan and a liver MRI was done only in the case of suspicion of liver metastasis.

\section{Treatment}

The treatment strategy consisted of first-line chemotherapy followed, in the absence of progression, by conformational chemoradiotherapy. Chemotherapy consisted of 4 to 6 cycles of the FOLFIRINOX regimen (oxaliplatin, irinotecan, 5FU-folinic acid) as first choice (8). Radiotherapy was a 3D conformal irradiation to the tumour volume, up to $59.4 \mathrm{~Gy}$ in 33 fractions over 6.5 weeks. Chemotherapy associated with radiotherapy consisted of a FOLFOX regimen (oxaliplatin, 5FU-folinic acid) as first choice, capecitabine $\left(1600 \mathrm{mg} / \mathrm{m}^{2} / \mathrm{j}\right.$ five days a week) or gemcitabine $\left(600 \mathrm{mg} / \mathrm{m}^{2} /\right.$ week $)$ in the case of FOLFOX contra-indication. Reassessment was carried out by the multidisciplinary team at the end of first-line chemotherapy and 4 to 6 weeks after the end of chemoradiotherapy. This reassessment 
was based on clinical signs and performance status, CA 19-9 levels and CT-scan evaluation in order to decide on surgical resection or not. Surgery was indicated in the case of tumour response or stability, performance status 0 or 1 and decrease of vascular abutment, or even, in the case of persistent vascular abutment images if limited to less than $180^{\circ}$ encasement. Adjuvant chemotherapy (gemcitabine) was proposed on MDT decision alone in the case of poor pathological features (R1 resection or major nodal involvement) and carried out depending on the patient's performance status.

\section{Surgical procedures and pathological protocol}

For resectable tumours, a classic Whipple procedure was carried out with an 'artery first' approach to determine resectability (9), with resection of the distal stomach without pylorus preservation, including removal of all lymph nodes as recommended by the International Study Group on Pancreatic Surgery (ISGPS) group (10). For the left side pancreatic cancer, a radical antegrade modular pancreatosplenectomy was performed. If persistent vascular abutment to the portal vein was found, a wedge or segmental resection was included in the procedure, and the venous segment was clearly identified. For segmental resection shorter than $3 \mathrm{~cm}$ end to end, anastomosis without graft was performed. In the case of segmental resection longer than $3 \mathrm{~cm}$ a peritoneal graft was used. The surgeon carried out inking of the circumferential margins before sending on to the pathologist in order to assist subsequent localization of the portal vein, the superior mesenteric vein groove, the superior mesenteric artery and the posterior margins (11). A macroscopic pathological procedure then followed a standardized protocol by serial slicing of the pancreatic head in a single axial plane, perpendicular to the longitudinal axis of the duodenum, to obtain slices covering the tumour and its ranges up to the inked margins (5). RO resection was defined as margin strictly superior to $0 \mathrm{~mm}$. R1 resection presented tumour cells on the inked margin. Surgical morbidity was defined as significant surgical postoperative complications of Grade III, IV or V, as classified by Dindo and Clavien (12). Grade III includes complications that required surgical, endoscopic or radiological 
intervention, with or without general anaesthesia. Grade IV includes life-threatening complications that require management in an intensive care unit. Grade $V$ complications cause postoperative death.

\section{Statistics}

The assessed end points were acute toxicity, post-operative mortality and morbidity occurring within 30 days post-surgery, subsequent surgery rate (RO or R1), local control rate, overall survival (OS) and progression free survival (PFS). The Kaplan-Meier method was used to estimate OS which was calculated from the date of diagnosis to the date of death or last follow-up. PFS was calculated from the date of diagnosis to the date of progression or the last follow-up.

Univariate and multivariate analyses of survival were done using a log-rank test and a stepwise Cox proportional hazards model, respectively. Univariate and multivariate analyses of the relationship between treatment factors (venous or arterial abutment, tumour size, CA19.9 level at initial staging, age, gender, tumour classification (LA vs BR)) and surgery were done using Chi-2 test or Fisher's exact and Whitney $U$ test or parametric Student's test for qualitative and quantitative variables respectively. The results were considered significant when $p$-value $<0.05$. Statistical analysis was carried out with R software, version 3.2.4. Analysis of the data was carried out in January 2016 so that a minimum 18 months follow-up was possible for all patients.

\section{Results}

\section{Patients}


Between 2010 and 2014, 79 patients (43 men, 36 women), with a median age of 60 years (range 3576) were included (Table 1). According to the NCCN v2-2017 classification, 41 and 38 patients respectively had baseline BR and LA unresectable tumours (Table 1).

\section{Neoadjuvant treatment}

All patients were treated by chemotherapy consisting of FOLFIRINOX (median number of cycles: 5 [113], resulting in Grade 3-4 toxicity for 4 patients (Grade 3 toxicities were asthenia, diarrhea and vomiting, whereas Grade 4 was a neutropenic infection). Chemotherapy was followed by chemoradiotherapy (3D conformational, median dose: $59 \mathrm{~Gy}$, range 45-66 Gy) for 74 patients (94\%). Ten patients were referred for radiotherapy to hospitals near their domicile, resulting in different total doses delivered. Four patients had metastatic disease and one presented local progression at the CT-scan assessment after chemotherapy and therefore did not have subsequent chemoradiotherapy. Radiotherapy was systematically associated with chemotherapy with FOLFOX regimen for 63 patients (85.1\%), gemcitabine for 2 patients (2.7\%), capecitabine for 6 patients $(8.1 \%)$ and oxaliplatin for 1 patient. Chemoradiotherapy was well tolerated in 72 patients (97.3\%) with a toxicity score inferior or equal to Grade 2. Oxaliplatin was stopped in one patient because of Grade 3 neuropathy. Three patients did not receive the entire treatment of chemoradiotherapy: two patients due to progression (peritoneum involvement revealed by ascites and small bowel occlusive syndrome) and one because of Grade 3 asthenia. In one patient, the CT-scan revealed liver metastases but also an aspect of duodenal perforation without any clinical symptom 8 weeks after the end of chemoradiotherapy.

\section{Surgical resection}

Among all patients, $37(46.8 \%)$ underwent surgery (Whipple procedure : 30 patients, radical antegrade modular pancreatosplenectomy: 7 patients) with a complete R0 resection in 34 (94\%). Regarding post-operative morbidity, 30 patients (81.1\%) had a Dindo score of 1 or 2 . Only five patients (13.5\%) had a Dindo 3-4: two patients with post pancreatectomy haemorrhage Grade B and 
five patients with post operative pancreatic fistula Grade C $(13,14)$. Post-operative mortality was 5.4\%. Two patients died within one month of surgery: one due to peritonitis and severe sepsis from post-operative fistula and the second due to haemorrhage.

Out of 74 patients who completed chemoradiotherapy, 13 were diagnosed with metastases and 16 with persistant vascular abutment at restaging by CT-scan. In addition, 7 patients had a surgical exploration but were not finally resected due to carcinomatosis (2), liver metastasis (1), nodal metastasis (1) or non resectable vascular contact.(3) Finally, 37 patients underwent surgical resection, 24 (58.5\%) with BR tumours initially, and 13 (34.2\%) with LA tumours initially (Figure 1). Twenty-three of the $37(62.2 \%)$ resected PDAC patients underwent a venous resection (portal vein and/or mesenteric vein); one of them also had a mesenteric artery resection and a hepatic artery reconstruction.

Four patients (11\%) received adjuvant chemotherapy with gemcitabine. For 2 patients, adjuvant chemotherapy was indicated by the MDT but could not be delivered due to infection (1 patient) and acute renal failure (1 patient).

\section{Pathological analysis}

Among the patients operated, 34 (94.4\%) had a R0 resection with 22 BR and 12 LA patients. Of note 28 patients $(75.6 \%)$ had limits $>1 \mathrm{~mm}$ (Table 2 ). Importantly, 13 patients had a complete or subcomplete response ypTO-T1NO (9 patients were initially BR and 4 patients were initially LA). One LA patient had a ypT1N1R0.

\section{Outcomes and survival}

Median follow-up was 48.8 months (range: $18.6-68$ months) for the entire population.

At the time of analysis, 56 patients had died: 27 (65.8\%) among BR patients and 29 (76.3 \%) among LA patients. Among operated patients, 15 (40.5\%) had no sign of recurrence, whereas 18 (48.6\%) saw 
metastatic progression (Figure 1). Noticeably, no local relapse, without metastasis, was evidenced in operated patients, and only 4 patients (10.8\%) had local relapses, but with systematic metastatic disease. In the non-operated group, only 2 patients (4.7\%) saw no progression. For 8 patients (19\%) progression was local, for $23(54.7 \%)$ it was metastatic and $9(21.4 \%)$ had both (Figure 1 ). The local control rate was significantly higher in the operated group with $89.2 \%$ as compared to $59.5 \%$ in the non-operated group $(p=0.01)$.

Median overall survival for the entire population was 21.5 months [CI95\%: 18-29 months].

Overall survival and progression-free survival were significantly different $(p<0.01)$ in favour of the operated group. The median OS was 49.7 months [CI95\%: 26.7-NR] for the operated group versus 17.4 months [CI95\%: 15.2-22.2] for the non-operated group (figure 2) and the median PFS was 25.5 months [CI95\%: 18.8-NR] for the operated group versus 9.2 months [CI95\%: 7.6-12.7] for the nonoperated group. Complete or sub-complete response ypT0-T1NO was associated with a significantly better overall survival compared to ypT2-4 or N1 (OR: 0.26 [CI95\%: 0.15-0.45]) (figure 3).

\section{Prognostic Factors}

In univariate analysis, the only prognostic factor of OS and of PFS was surgical resection $(p<0.001)$. Other parameters were not significantly associated. Therefore no multivariate analysis was performed. Five main factors were significantly related to decreased probability of secondary surgery: abutment with the superior mesenteric artery and hepatic artery, arterial contact, initial classification as LA, and post-chemoradiotherapy CA $19-9 \geq 20 \mathrm{U} / \mathrm{mL}$. In the case of abutment with the superior mesenteric artery, only $34.9 \%$ of patients were operated versus $61.1 \%$ with no contact $(p=0.022, O R=0.34[0.14-0.85])$. For hepatic artery abutment, this ratio was 28 versus $55.6 \%$ of patients $(p=0.026, O R=0.31[0.11-0.87])$. Initial classification as $B R$ was linked to increased probability of surgery $(p=0.032, O R=2.71[1.09-6.77])$ compared with LA (Table 3$)$. Finally $36.7 \%$ of patients with a 
post-chemoradiotherapy Ca19.9 $\geq 20 \mathrm{U} / \mathrm{mL}$ were operated versus $64.3 \%$ of patients with a CA $19-9$ $<20 \mathrm{U} / \mathrm{mL}(\mathrm{p}=0.036, \mathrm{OR}=3.11[1.06-9.09])$.

\section{Discussion}

The aim of this retrospective study was to determine the tolerance, secondary resection rate and patient outcome after a neoadjuvant or induction strategy including FOLFIRINOX-based chemotherapy followed by chemoradiotherapy, for patients with BR or LA pancreatic cancers. R0 resection is associated with a better outcome $(2,5)$.. We therefore hypothesized that neoadjuvant treatment could allow secondary resection in PDAC considered as locally advanced at baseline and increase the RO resection rate in BR cancers. This was further supported by the fact that even if a tumour is considered as BR and can be resectable at the cost of venous resection, the risk of R1 resection remains major. Furthermore, even if $\mathrm{R} 0$ resections are achieved, venous resection has been identified as an unfavourable prognostic factor (15).

Firstly, we found that neoadjuvant treatment was well-tolerated with less than $3 \%$ of Grade 3-4 toxicity, and $90 \%$ of patients completing the treatment schedule. This is in agreement with the results of the AGEO cohort with FOLFIRINOX neoadjuvant chemotherapy (16). Furthermore, postoperative mortality was $5 \%$, similar to published results of upfront pancreatectomy (17), and in agreement with Liu's meta-analysis that found similar post-operative mortality rates between patients operated with or without neoadjuvant chemoradiotherapy in resectable patients (18). Interestingly, some authors report even less frequent post-operative complications in patients operated after neoadjuvant chemoradiotherapy in particular regarding pancreatic fistula $(19,20)$.

Secondly, we found that this neoadjuvant strategy achieved $47 \%$ of secondary resections with $94 \%$ RO resections when $\mathrm{R} 0$ resection means $>0 \mathrm{~mm}$ but $75.6 \%$ if $\mathrm{RO}$ means $\geq 1 \mathrm{~mm}$. These results are slightly comparable to the $69.5 \%(\mathrm{Cl} 62.1 \%-76.4 \%)$ rate of exploration with resection in $77.9 \%$ (Cl 
$72.4 \%-82.9 \%)$ of cases published in the meta-analysis by Gillen et al., combining the results of 111 studies, including LA and BR patients (4). However, our complete resection rate was higher than or in the range of previously published rates ( 72.4 to $85.2 \%$ ) depending on $\mathrm{RO}$ definition ( $>0 \mathrm{~mm}$ or $\geq$ $1 \mathrm{~mm})(4,21,22)$. Differences in the proportion of LA versus BR pancreatic cancers in the published studies might explain variations in resection rates. Interestingly, a secondary resection was possible for $34.2 \%$ of LA initially non resectable tumours, with $92.3 \%$ R0 resection, compared to $26 \%$ in the meta-analysis of Suker et al. which included 355 patients treated by induction FOLFIRINOX for LA PDAC. Of note, $63.5 \%$ of patients received chemoradiotherapy after induction chemotherapy. Our result is in agreement with the one third of secondary resection rate published in 3 different metaanalyses $(4,22,23)$. This carries strong clinical value, given the fact that chemoradiotherapy still remains controversial in this context. Indeed, chemoradiotherapy is considered as an option after neoadjuvant chemotherapy since it results in improved time without treatment compared to chemotherapy alone, but without improvement in survival (24). Chemoradiotherapy may enable vascular abutments to be sterilized. Therefore, it is a strong therapeutic option from the point of view of converting non resectable tumours to resectability, or in increasing the rate of complete RO resection, as shown in the AGEO study (25). It might also play a role in identifying patients with rapid progressive or metastatic disease, for whom frontline surgery would not be beneficial.

For BR tumours, our study found a $58.5 \%$ secondary resection rate, R0 in $95 \%$ of cases, consistent with published results, which however show great variability. Several reasons can explain the wide heterogeneity of published $\mathrm{R} 0$ resection rates $(4,18-20)$.

Firstly, resectability criteria are still debated. Several definitions have been proposed for LAPC depending on the extent of vascular contact, such as the M.D.Anderson or the Callery consensus (26). The main classification used is the NCCN classification which is, however, regularly updated, leading to potential retrospective differences in the distribution of patients among the groups (BR versus $L A)(3)$. Secondly, resection rates could also depend on the multidisciplinary decision at assessment after neoadjuvant treatment. Indeed, analysis of resectability after neoadjuvant 
treatment is even more challenging since post-treatment images are difficult to analyze. The ability to predict R0 resectability with a CT-scan was reduced in the case of neoadjuvant treatment $(58 \%$ versus $83 \%, p=0.039$ ) mostly due to overestimation of tumour size and vascular contacts and a diffuse peripancreatic inflammation (26-28).

Biopsies by laparoscopy are recommended to rule out secondary site or persistence of vascular abutment. Thirdly, the sequential surgical strategy carried out in our institution could also influence the secondary resection rate. After the absence of carcinomatosis has been verified, biopsies of persistent arterial vascular abutment are carried out with extemporaneous histopathological analysis. Resection is continued only in the case of sterilization of biopsies, with venous resection if necessary (6) Fourthly, Ro resection is also dependent on a systematic and standardized histopathological analysis protocol. Resection specimen orientation and margin inking by the surgeon are critical. In addition, R0 rates vary among studies, between $77 \%$ if $\mathrm{R} 0$ means margins are over 0 $\mathrm{mm}$, and $29 \%$ if RO means margins are over $2 \mathrm{~mm}(5,29)$.

Prognostic factors associated with secondary resection were as already published, in particular arterial abutments with SMA, and were in agreement with definition of LA. Venous invasion, initial tumour size and initial CA19-9 were not associated with resectability $(29,30)$. However, a postchemoradiotherapy Ca19.9 under 20 was associated with resectability.

Our survival results are in the range (13.7-24.2 months) found for LA PDAC treated with FOLFIRINOX regimen as a first line treatment (22). Importantly, overall survival results were remarkably high in operated patients (49.7 [IC95\%: 26.7-NR]). In addition, overall survival was significantly higher in patients with complete or sub-complete ypTO-T1NOMO response (respectively NR versus 26.6 months, (OR: 0.26 [CI95\%: 0.15-0.45])), which may be an argument for intensification of neoadjuvant treatment. Noticeably, the local control rate was high in patients treated by chemoradiotherapy and surgery with no local relapse, without metastasis and only $10.8 \%$ local relapses but with systematic metastatic disease, whereas frontline surgery is usually associated with 35 to $86 \%$ of local relapse 
(28-30), suggesting the high relevance of this strategy even for patients with initially resectable tumours.

Therefore we can't exclude a bias of selection of patients, leading to favourable results. Indeed, our recruitment was mainly done by the hepato-biliary and pancreatic surgery department, with patients referred for surgery from primary and secondary centres, explaining our high rate of BR patients (52\%), which does not reflect the general recruitment in this pathology. However, this also proves the expertise of our centre, practicing $>65$ pancreatectomies per year, knowing that the annual caseload of pancreatectomy has been shown to be an independent predictor of mortality (17).

In addition, the decision for resectability could vary among physicians according to the time of decision, since classification has evolved during the timeline of the cohort treatment. To address this issue, we decided to carry out a central review of all patient CT-scan imaging according to the latest version of classification at the time of analysis, in order to make patient distribution consistant according to resectability criteria.

In conclusion, our data confirms that neoadjuvant treatment consisting of FOLFIRINOX chemotherapy followed by chemoradiotherapy is an efficient strategy for patients with BR and LA pancreatic cancers, resulting in a good rate of secondary complete surgical resection and pathological response. Furthermore, well-tolerated, this strategy results in high local control of the disease. Ongoing randomized prospective clinical trials are currently testing this therapeutic approach.

\section{References:}

1. Lutz MP, Zalcberg JR, Ducreux M, Aust D, Bruno MJ, Büchler MW, et al. 3rd St. Gallen EORTC Gastrointestinal Cancer Conference: Consensus recommendations on controversial issues in the primary treatment of pancreatic cancer. Eur J Cancer. 2017 Jul;79:41-9.

2. Neoptolemos JP, Stocken DD, Dunn JA, Almond J, Beger HG, Pederzoli P, et al. Influence of resection margins on survival for patients with pancreatic cancer treated by adjuvant 
chemoradiation and/or chemotherapy in the ESPAC-1 randomized controlled trial. Ann Surg. 2001;234(6):758.

3. Tempero MA, Malafa MP, Al-Hawary M, Asbun H, Bain A, Behrman SW, et al. Pancreatic Adenocarcinoma, Version 2.2017, NCCN Clinical Practice Guidelines in Oncology. J Natl Compr Canc Netw. 2017 Aug;15(8):1028-61.

4. Gillen S, Schuster T, Meyer zum Büschenfelde C, Friess H, Kleeff J. Preoperative/Neoadjuvant Therapy in Pancreatic Cancer: A Systematic Review and Meta-analysis of Response and Resection Percentages. Seiler C, editor. PLoS Med. 2010 Apr 20;7(4):e1000267.

5. Delpero JR, Bachellier P, Regenet N, Le Treut YP, Paye F, Carrere N, et al. Pancreaticoduodenectomy for pancreatic ductal adenocarcinoma: a French multicentre prospective evaluation of resection margins in 150 evaluable specimens. HPB. 2014 Jan;16(1):20-33.

6. Denost $\mathrm{Q}$, Laurent $\mathrm{C}$, Adam J, Capdepont $\mathrm{M}$, Vendrely V, Collet $\mathrm{D}$, et al. Pancreaticoduodenectomy following chemoradiotherapy for locally advanced adenocarcinoma of the pancreatic head. HPB. 2013 Sep;15(9):716-23.

7. Neuzillet C, Tijeras-Raballand A, Bourget P, Cros J, Couvelard A, Sauvanet A, et al. State of the art and future directions of pancreatic ductal adenocarcinoma therapy. Pharmacol Ther. 2015;155:80-104.

8. Balaban EP, Mangu PB, Khorana AA, Shah MA, Mukherjee $\mathrm{S}, \mathrm{Crane} \mathrm{CH}$, et al. Locally Advanced, Unresectable Pancreatic Cancer: American Society of Clinical Oncology Clinical Practice Guideline. J Clin Oncol. 2016 Aug;34(22):2654-68.

9. Sanjay P, Takaori K, Govil S, Shrikhande SV, Windsor JA. 'Artery-first' approaches to pancreatoduodenectomy. Br J Surg. 2012 Aug;99(8):1027-35. 
10. Tol JAMG, Gouma DJ, Bassi C, Dervenis C, Montorsi M, Adham M, et al. Definition of a standard lymphadenectomy in surgery for pancreatic ductal adenocarcinoma: A consensus statement by the International Study Group on Pancreatic Surgery (ISGPS). Surgery. 2014 Sep;156(3):591600.

11. Adsay NV, Basturk O, Saka B, Bagci P, Ozdemir D, Balci S, et al. Whipple Made Simple For Surgical Pathologists: Orientation, Dissection, and Sampling of Pancreaticoduodenectomy Specimens For a More Practical and Accurate Evaluation of Pancreatic, Distal Common Bile Duct, and Ampullary Tumours. Am J Surg Pathol. 2014 Apr;38(4):480-93.

12. Dindo D, Demartines N, Clavien P-A. Classification of Surgical Complications: A New Proposal With Evaluation in a Cohort of 6336 Patients and Results of a Survey. Ann Surg. 2004 Aug;240(2):205-13.

13. Wente MN, Veit JA, Bassi C, Dervenis C, Fingerhut A, Gouma DJ, et al. Postpancreatectomy hemorrhage (PPH)-An International Study Group of Pancreatic Surgery (ISGPS) definition. Surgery. 2007 Jul;142(1):20-5.

14. Bassi C, Marchegiani G, Dervenis C, Sarr M, Abu Hilal M, Adham M, et al. The 2016 update of the International Study Group (ISGPS) definition and grading of postoperative pancreatic fistula: 11 Years After. Surgery. 2017 Mar;161(3):584-91.

15. Delpero JR, Boher JM, Sauvanet A, Le Treut YP, Sa-Cunha A, Mabrut JY, et al. Pancreatic Adenocarcinoma with Venous Involvement: Is Up-Front Synchronous Portal-Superior Mesenteric Vein Resection Still Justified? A Survey of the Association Française de Chirurgie. Ann Surg Oncol. 2015 Jun;22(6):1874-83. 
16. Marthey L, Sa-Cunha A, Blanc JF, Gauthier M, Cueff A, Francois E, et al. FOLFIRINOX for Locally Advanced Pancreatic Adenocarcinoma: Results of an AGEO Multicentre Prospective Observational Cohort. Ann Surg Oncol. 2014;22(1):295-301.

17. Farges O, Bendersky N, Truant S, Delpero JR, Pruvot FR, Sauvanet A. The Theory and Practice of Pancreatic Surgery in France: Ann Surg. 2017 Nov;266(5):797-804.

18. Liu W, Fu X-L, Yang J-Y, Liu D-J, Li J, Zhang J-F, et al. Efficacy of Neo-Adjuvant Chemoradiotherapy for Resectable Pancreatic Adenocarcinoma: A PRISMA-Compliant MetaAnalysis and Systematic Review. Medicine (Baltimore). 2016 Apr;95(15):e3009.

19. Sho M, Akahori T, Tanaka T, Kinoshita S, Nagai M, Nishiwada S, et al. Optimal indication of neoadjuvant chemoradiotherapy for pancreatic cancer. Langenbecks Arch Surg. 2015 May;400(4):477-85.

20. Takahashi H, Ogawa H, Ohigashi H, Gotoh K, Yamada T, Ohue M, et al. Preoperative chemoradiation reduces the risk of pancreatic fistula after distal pancreatectomy for pancreatic adenocarcinoma. Surgery. 2011 Sep;150(3):547-56.

21. Suker M, Beumer BR, Sadot E, Marthey L, Faris JE, Mellon EA, et al. FOLFIRINOX for locally advanced pancreatic cancer: a systematic review and patient-level meta-analysis. Lancet Oncol. 2016 Jun;17(6):801-10.

22. Petrelli F, Coinu A, Borgonovo K, Cabiddu M, Ghilardi M, Lonati V, et al. FOLFIRINOX-based neoadjuvant therapy in borderline resectable or unresectable pancreatic cancer: a metaanalytical review of published studies. Pancreas. 2015;44(4):515-521.

23. Assifi MM, Lu X, Eibl G, Reber HA, Li G, Hines OJ. Neoadjuvant therapy in pancreatic adenocarcinoma: A meta-analysis of phase II trials. Surgery. 2011 Sep;150(3):466-73. 
24. Hammel P, Huguet F, van Laethem J-L, Goldstein D, Glimelius B, Artru P, et al. Effect of Chemoradiotherapy vs Chemotherapy on Survival in Patients With Locally Advanced Pancreatic Cancer Controlled After 4 Months of Gemcitabine With or Without Erlotinib: The LAP07 Randomized Clinical Trial. JAMA. 2016 May 3;315(17):1844.

25. Pietrasz D, Turrini O, Vendrely V, Simon J-M, Hentic O, Coriat R, et al. How Does Chemoradiotherapy Following Induction FOLFIRINOX Improve the Results in Resected Borderline or Locally Advanced Pancreatic Adenocarcinoma? An AGEO-FRENCH Multicentric Cohort. Ann Surg Oncol [Internet]. 2018 Oct 25 [cited 2018 Nov 17]; Available from: http://link.springer.com/10.1245/s10434-018-6931-6

26. Choti MA, Dixon E, Tyler D. Pretreatment Assessment of Resectable and Borderline Resectable Pancreatic Cancer: Expert Consensus Statement by Callery et al. Ann Surg Oncol. 2009 Jul;16(7):1734-5.

27. Cassinotto C, Cortade J, Belleannée G, Lapuyade B, Terrebonne E, Vendrely V, et al. An evaluation of the accuracy of CT when determining resectability of pancreatic head adenocarcinoma after neoadjuvant treatment. Eur J Radiol. 2013 Apr;82(4):589-93.

28. Wagner M, Antunes C, Pietrasz D, Cassinotto C, Zappa M, Sa Cunha A, et al. CT evaluation after neoadjuvant FOLFIRINOX chemotherapy for borderline and locally advanced pancreatic adenocarcinoma. Eur Radiol. 2017 Jul;27(7):3104-16.

29. Schlitter AM, Esposito I. Definition of Microscopic Tumour Clearance (RO) in Pancreatic Cancer Resections. Cancers. 2010 Nov 25;2(4):2001-10.

30. Fuhrman GM, Charnsangavej C, Abbruzzese JL, Cleary KR, Martin RG, Fenoglio CJ, et al. Thinsection contrast-enhanced computed tomography accurately predicts the resectability of malignant pancreatic neoplasms. Am J Surg. 1994;167(1):104-113. 
31. Breidert M, Keck T, Makowiec F, Lohrmann C, Harder J, Fischer R. Early recurrence of pancreatic cancer after resection and during adjuvant chemotherapy. Saudi J Gastroenterol. 2012;18(2):118.

32. Van den Broeck A, Sergeant G, Ectors N, Van Steenbergen W, Aerts R, Topal B. Patterns of recurrence after curative resection of pancreatic ductal adenocarcinoma. Eur J Surg Oncol [Internet]. 2009;35.

33. HabermehI D, Brecht IC, Bergmann F, Welzel T, Rieken S, Werner J, et al. Chemoradiation in patients with isolated recurrent pancreatic cancer - therapeutical efficacy and probability of reresection. Radiat Oncol. 2013 Jan 31;8(1):27.

\section{Figure captions}

\section{Figure 1: Patients' outcome}

PDAC: Pancreatic Ductal Adenocarcinoma; LA: Locally advanced; BR: Borderline; CT: CT-scan

\section{Figure 2: Overall survival according to surgery}

Kaplan-Meier estimates of overall survival (OS) were significantly different $(p<0.01)$ in favour of operated versus non-operated patients. The median survival time was estimated to be 49.7 months [CI95\%:26.7-NR] in the operated group versus 17.4 months [CI95\%:15.2-22.2] in the non-operated group.

Figure 3. Overall survival according to complete/sub-complete response

Kaplan-Meier estimates of overall survival (OS) in months were significantly different in favour of patients with complete or sub-complete response. Median survival time was not reached for 
patients achieving ypT0-1, N0 versus 26.6 months for patients with ypT2-4 or N1 (OR: 0.26 [CI95\%: 0.15-0.45]). 


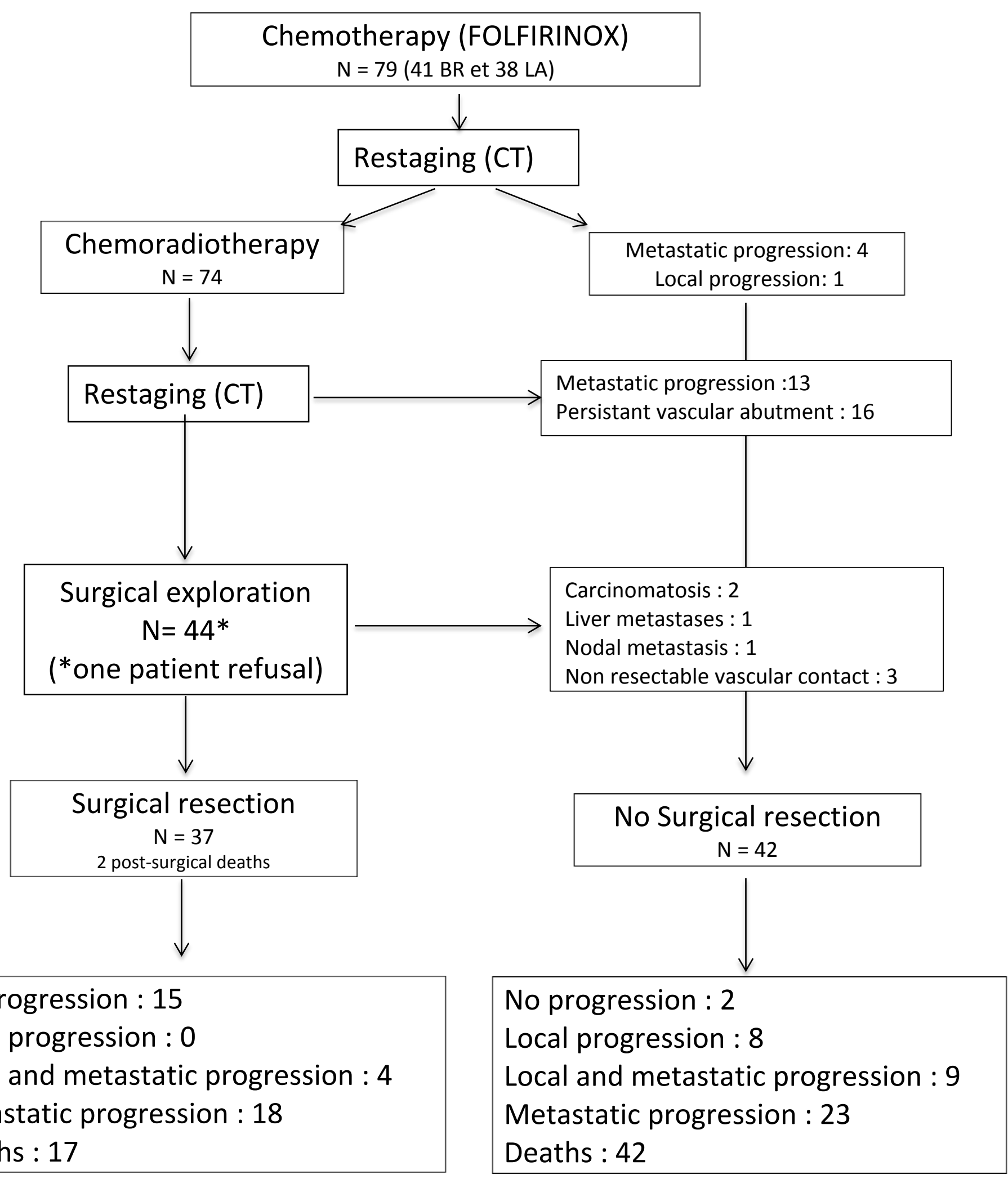

No progression : 15

Local progression : 0

Local and metastatic progression : 4

Metastatic progression : 18

Deaths : 17
Carcinomatosis : 2

Liver metastases : 1

Nodal metastasis : 1

Non resectable vascular contact : 3

\section{No Surgical resection}

$\mathrm{N}=42$

No progression : 2

Local progression : 8

Local and metastatic progression : 9

Metastatic progression : 23

Deaths : 42 


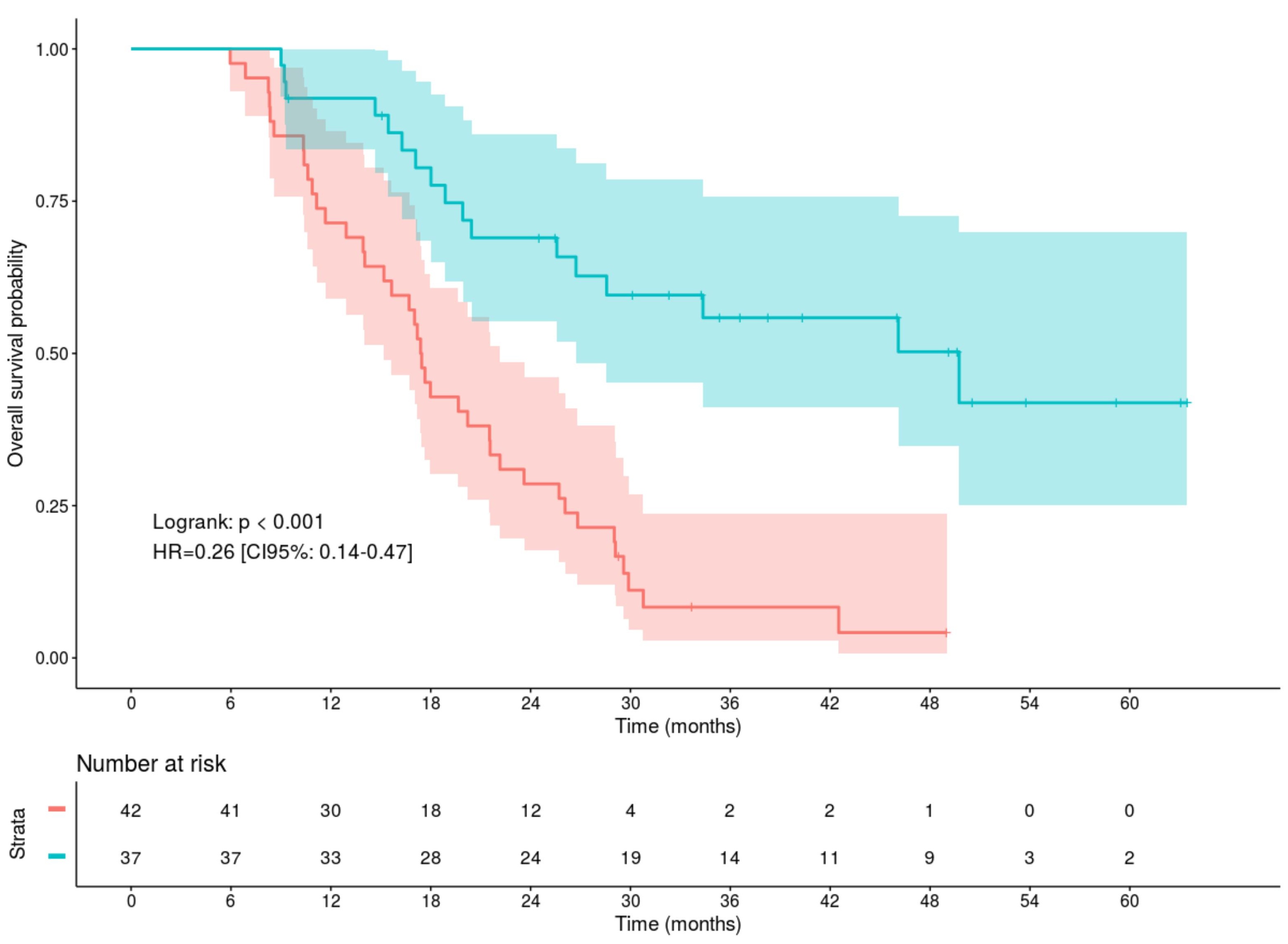


Strata + ypT0-1,N0 - ypT2-4 or N1

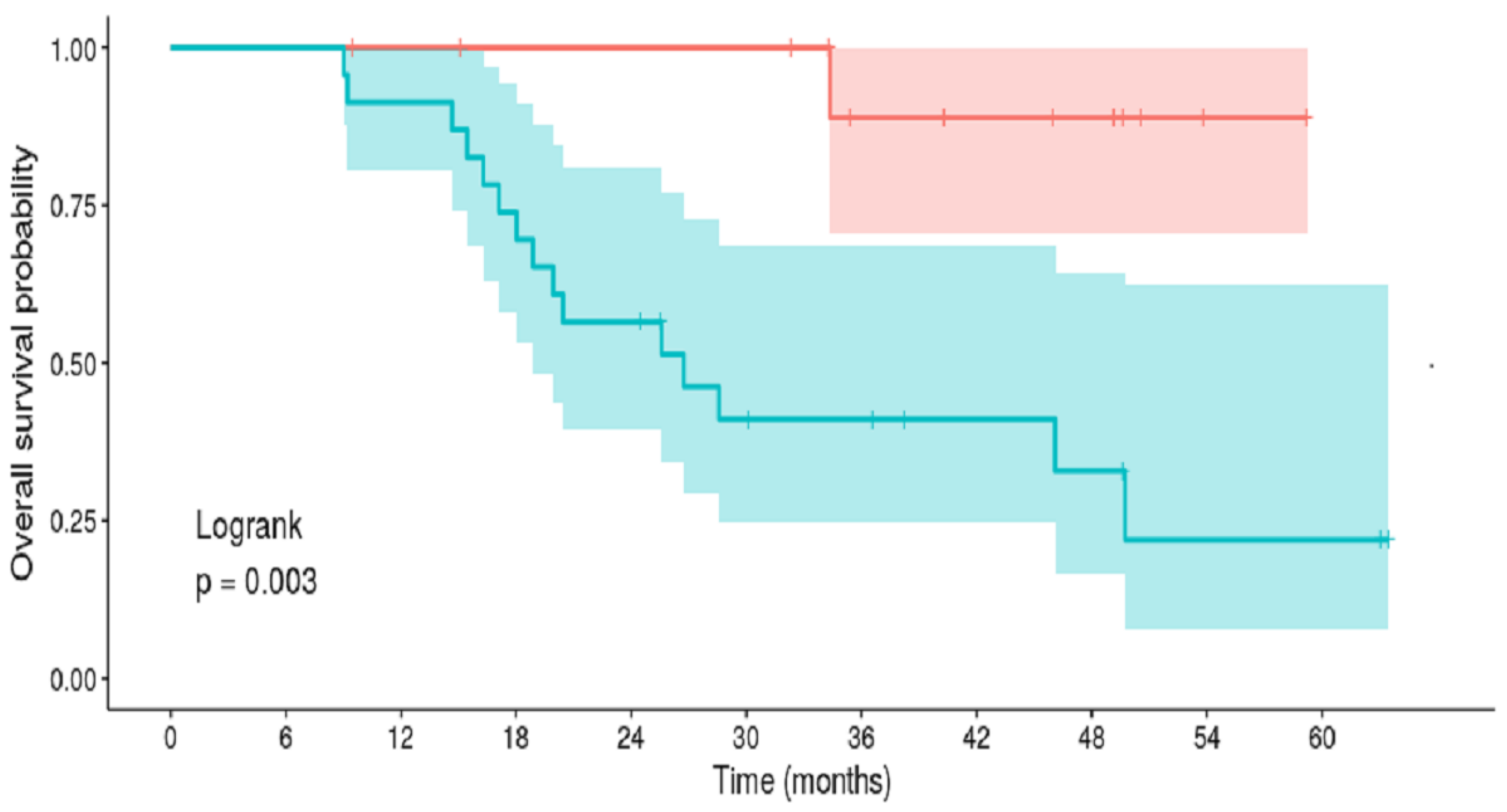

Number at risk

\begin{tabular}{|c|c|c|c|c|c|c|c|c|c|c|c|}
\hline \multirow{2}{*}{ 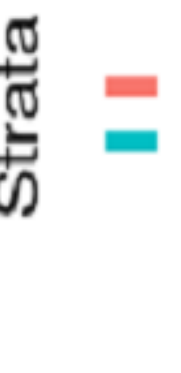 } & $\begin{array}{r}13 \\
23 \\
\end{array}$ & $\begin{array}{r}13 \\
23 \\
\end{array}$ & $\begin{array}{l}12 \\
21\end{array}$ & 11 & 13 & $\begin{array}{l}11 \\
8\end{array}$ & 7 & $\begin{array}{l}6 \\
5\end{array}$ & 5 & 2 & 8 \\
\hline & 0 & 6 & 12 & 18 & 24 & $\begin{array}{r}30 \\
\text { Time }\end{array}$ & $\begin{array}{r}36 \\
\text { nthe }\end{array}$ & 42 & 48 & 54 & 60 \\
\hline
\end{tabular}




\begin{tabular}{lcc}
\hline Patient characteristics & $\mathbf{N}$ & $\mathbf{\%}$ \\
\hline Age & & \\
$<65$ & 50 & 63.3 \\
$\geq 65$ & 29 & 36.7 \\
Gender & & \\
Male & 43 & 58.9 \\
Female & 36 & 45.5 \\
Initial OMS status & & \\
$\mathbf{0}$ & 24 & 30.4 \\
$\mathbf{1}$ & 48 & 60.8 \\
$\mathbf{2}$ & 7 & 8.9 \\
Initial CA 19-9(Ui/ml) & 175 & $0.9-11927$ \\
(median/range) & & \\
Tumor characteristics & & \\
Borderline & 41 & $\mathbf{5 1 . 9}$ \\
$\quad$ Arterial contact & 22 & $53.7^{*}$ \\
$\quad$ Venous contact & 40 & $97.6^{*}$ \\
Locally advanced & 38 & 48.1 \\
$\quad$ Arterial contact & 37 & $97.4^{* *}$ \\
$\quad$ Venous contact & 32 & $84.2^{* *}$ \\
\hline
\end{tabular}

Table 1: Patients and tumor characteristics at initial staging

*percentage among patients with borderline tumors

** percentage among patients with locally advanced tumors

DLD-18-692 


\begin{tabular}{ccc}
\hline Histological results & Borderline & Locally advanced \\
\hline Surgical resection $(\mathbf{N})$ & $24(1$ no histology $)$ & $\mathbf{1 3}$ \\
ypT0-T1 & 9 & $\mathbf{5}$ \\
ypT2-T3-T4 & 14 & $\mathbf{8}$ \\
ypN0 & 18 & $\mathbf{9}$ \\
ypN1 & 5 & 4 \\
ypM1 & 1 (node) \\
R0 & 22 & 12 \\
R1 & 1 & $\mathbf{1}$ \\
ypTONORO & 3 & 4 \\
\hline
\end{tabular}

Table 2. Histological results according to the initial tumour classification 


\begin{tabular}{|c|c|c|c|c|c|c|}
\hline Parameters & Modality & $\mathbf{N}$ & $\%$ & OR & $\mathrm{Cl}$ & $P$ value \\
\hline SMA contact & $\begin{array}{l}\text { No Contact } \\
\text { Contact }\end{array}$ & $\begin{array}{l}36 \\
43\end{array}$ & $\begin{array}{l}61.1 \\
34.9\end{array}$ & $\begin{array}{c}- \\
0.34\end{array}$ & $0.14-0.85$ & 0.022 \\
\hline $\begin{array}{l}\text { Coeliac axis } \\
\text { contact }\end{array}$ & $\begin{array}{l}\text { No contact } \\
\text { Contact }\end{array}$ & $\begin{array}{l}60 \\
19\end{array}$ & $\begin{array}{l}51.7 \\
31.6\end{array}$ & $\begin{array}{c}- \\
0.43\end{array}$ & $0.14-1.29$ & 0.132 \\
\hline $\begin{array}{l}\text { Hepatic artery } \\
\text { contact }\end{array}$ & $\begin{array}{l}\text { No contact } \\
\text { Contact }\end{array}$ & $\begin{array}{l}54 \\
25\end{array}$ & $\begin{array}{l}55.6 \\
28\end{array}$ & $\begin{array}{c}- \\
0.31 \\
\end{array}$ & $0.11-0.87$ & 0.026 \\
\hline Arterial contact & $\begin{array}{l}\text { No contact } \\
\text { Contact }\end{array}$ & $\begin{array}{l}20 \\
59\end{array}$ & $\begin{array}{l}70 \\
39\end{array}$ & $\begin{array}{l}- \\
0.27\end{array}$ & $0.09-0.81$ & 0.02 \\
\hline $\begin{array}{l}\text { Retroportal } \\
\text { infiltration }\end{array}$ & $\begin{array}{l}\text { No } \\
\text { Yes }\end{array}$ & $\begin{array}{l}37 \\
42 \\
\end{array}$ & $\begin{array}{l}43.2 \\
50\end{array}$ & $\begin{array}{c}- \\
1.31 \\
\end{array}$ & $0.54-3.19$ & 0.548 \\
\hline SMV contact & $\begin{array}{l}\text { No contact } \\
\text { Contact }\end{array}$ & $\begin{array}{l}19 \\
60\end{array}$ & $\begin{array}{l}42.1 \\
48.3\end{array}$ & $\begin{array}{l}- \\
1.29\end{array}$ & $0.45-3.65$ & 0.636 \\
\hline SMV stenosis & $\begin{array}{l}0 \\
\text { Inferior to } 50 \% \\
\text { Superior to } 50 \%\end{array}$ & $\begin{array}{l}56 \\
7 \\
16\end{array}$ & $\begin{array}{l}42.9 \\
85.7 \\
43.8\end{array}$ & $\begin{array}{l}8^{-} \\
1.04\end{array}$ & $\begin{array}{l}0.9-70.93 \\
0.34-3.18\end{array}$ & $\begin{array}{l}0.062 \\
0.949\end{array}$ \\
\hline Venous contact & $\begin{array}{l}\text { No contact } \\
\text { Contact }\end{array}$ & $\begin{array}{l}7 \\
72\end{array}$ & $\begin{array}{l}42.9 \\
47.2\end{array}$ & $\begin{array}{c}- \\
1.19\end{array}$ & $0.25-5.72$ & 0.825 \\
\hline Classification & $\begin{array}{l}\text { Locally advanced } \\
\text { Borderline }\end{array}$ & $\begin{array}{l}38 \\
41\end{array}$ & $\begin{array}{l}34.2 \\
58.5\end{array}$ & $\begin{array}{c}- \\
2.71\end{array}$ & $1.09-6.77$ & 0.032 \\
\hline $\begin{array}{l}\text { Pre-CRT Ca19.9 } \\
\text { (Ui/ml) }\end{array}$ & $\begin{array}{l}<175 \\
\geq 175\end{array}$ & $\begin{array}{l}33 \\
33\end{array}$ & $\begin{array}{l}57.6 \\
36.4\end{array}$ & $\begin{array}{c}- \\
0.42\end{array}$ & $0.16-1.13$ & 0.087 \\
\hline $\begin{array}{l}\text { After CRT Ca } 19.9 \\
(\mathrm{Ui} / \mathrm{ml})\end{array}$ & $\begin{array}{l}\geq 20 \\
<20\end{array}$ & $\begin{array}{l}30 \\
28 \\
\end{array}$ & $\begin{array}{l}36.7 \\
64.3 \\
\end{array}$ & 3.11 & $1.06-9.08$ & 0.036 \\
\hline Age (years) & $\begin{array}{l}<65 \\
\geq 65\end{array}$ & $\begin{array}{l}50 \\
29\end{array}$ & $\begin{array}{l}46 \\
48.3\end{array}$ & 1.1 & $0.44-2.74$ & 0.845 \\
\hline $\begin{array}{l}\text { Performance } \\
\text { status (OMS) }\end{array}$ & $\begin{array}{l}0 \\
1 \\
2\end{array}$ & $\begin{array}{l}48 \\
24 \\
7\end{array}$ & $\begin{array}{l}41.7 \\
62.5 \\
28.6\end{array}$ & $\begin{array}{l}2.33 \\
0.56\end{array}$ & $\begin{array}{l}0.85-6.38 \\
0.1-3.18\end{array}$ & $\begin{array}{l}0.099 \\
0.513\end{array}$ \\
\hline Tumor size (mm) & $\begin{array}{l}<35 \\
\geq 35\end{array}$ & $\begin{array}{l}37 \\
39\end{array}$ & $\begin{array}{l}56.8 \\
35.9\end{array}$ & $\begin{array}{l}- \\
0.43\end{array}$ & $0.17-1.07$ & 0.07 \\
\hline
\end{tabular}

Table 3: Parameters associated with resectability :OR(odds ratio), $\mathrm{Cl}$ (confidence interval) 